\title{
The Solution of Credit Mechanism in Electronic Commerce Transactions
}

\author{
Xiongying SUN, Lili YANG \\ Zhejiang Business Technology Institute, Ningbo, 315012, China \\ email:xiongying_sun@163.com
}

Keywords: Electronic Commerce; Credit Mechanism; Solution

\begin{abstract}
With the arrival of Electronic Commerce, many people have become interested in trust issues. Most people agree that in order for Electronic Commerce to become a success the people have to trust it. Trust in Electronic Commerce is thus an important subject. The basic assumption of the model is that an individual will only engage in a transaction if his level of trust exceeds his personal threshold, which depends on the type of transaction and other parties involved in the transaction. Idea of Electronic Commerce trust is briefly introduced. Concepts, character, attack cost and attack effectiveness of attack are described, and analyzing all kinds of attack model in Electronic Commerce systems.
\end{abstract}

\section{Introduction}

Today, e-commerce as one of the most important industries of the modern service industry, "there is a sunrise industry, green industry, and has a" three high "," three new "characteristics. "Three high" that the high level of human capital, high technology content and high added value, the "three new" refers to the new technologies, new formats, new way. The electronic commerce industry at the same time, with the globalization of markets, continuous trading, low cost, resource intensive and other advantages, so in these new trade opportunities in the fields of subtle but because of the traditional trades made on one hand, one hand delivery, and electronic commerce without geographical and time constraints. Only relying on the network trading platform, trading in the benefits have been markedly improved. At the same time, the limitations of this transaction model are also increasingly prominent. Cannot be denied that the business behind, but also hidden traps and huge potential of "good faith".

In China, credit problem has been one of the important bottlenecks that restrict the development of electronic commerce. In the modern electronic business activities, a series of automated system greatly simplifies the transaction process, improve the efficiency of the transaction at the same time also increased the degree of asymmetric information. Behind the appearance of prosperity of e-commerce is hidden is the lack of good faith, the loss of integrity, business transaction security is lost. Therefore, how to "honesty and credit" the commercial "imperial rule" implemented in e-commerce transactions, and establishes a set of effective security mechanism of electronic commerce has become an important part of electronic commerce and the healthy and sustainable development is particularly important.

With the development of electronic commerce, electronic trading means more diverse, the integrity of the security issues will become more important and prominent. The electronic commerce and the electronic commerce credit system are in fact inseparable, the two complement each other, are: lack of integrity as the foundation of the network security has become empty, transaction security cannot be guaranteed. Without a secure network environment, can make the electronic commerce to a keep integrity requirements. Therefore, only two pronged approach, to improve and development, in order to ensure smooth and stable e-commerce transactions, e-commerce development in China will be promising.

\section{The credit crisis of electronic commerce}

The electronic commerce credit crisis is actually a reflection of the crisis of trust, in the realistic economic life at present; the credit crisis is mainly manifested in the electronic commerce: 
Internet fraud: In e-commerce, e-commerce information is relative to the less constrained by the subject in traditional media. Consumers find information error, it is difficult to pursue to the electronic commerce main body to release information, or even simply do not know the subject of electronic commerce. Therefore, some of the electronic commerce main body is bent solely on profit, bank fraud, using various means to entice consumers deceived. The majority of consumers have doubts about the Internet a lot of information, loss of trust, actively using the Internet to purchase goods and services to reduce.

The goods quality problems: The necessary constraint part of subject of electronic commerce in the course of business because of its lack of moral and legal, not good, the manufacture and sale of fake and shoddy products, profiteering, resulting in consumer e-commerce market on product quality trust degree is very bad.

Credit and payment issues: The use of e-commerce transactions will inevitably involve credit payment. But due to the lack of the spirit of good faith and sense of trust between people of poor people in order to avoid the risk of not dare rushed through the network of their own credit card account to tell enterprises. Therefore, the majority of enterprises engaged in e-commerce, the payment of the goods to the reliable; do not trust each other to solve the problem of the payment of both sides. But the traditional cash payment for online transactions, contrary to the original intention of electronic commerce.

\section{The electronic commerce and the honesty and credit}

As the name suggests is to be honest, honest, and trustworthy. Honesty and credit is the internal requirement of the development of market economy, electronic commerce and the traditional business activities, the essence is the same, it also needs to pay attention to honesty and credit, but because of the anonymity and openness of the Internet electronic commerce put forward higher requirements on credit.

The establishment of credit mechanism is the needs of e-commerce development. The electronic commerce credit refers to the subject of electronic commerce in the relevant transaction with "good faith", "honesty" and "credit" good subjective state of mind. In the electronic commerce in the various fields of the national economy is becoming more and more popular, the establishment of the integrity of the environment for the development of e-commerce is conducive to the benign development of the electronic commerce.

Establish credit mechanism is decided by the characteristic of e-commerce. Open, global, low cost, high efficiency and other characteristics of the Internet itself has, has become an important reason for the rapid development of electronic commerce; however, the Internet itself is non-center, virtual, cross regional and a high degree of autonomy, have online illegal acts of concealment, low cost and convenience, to bring a large number of the credit crisis, which has become the rapid development of electronic commerce obstacles. Three construction of electronic commerce credit mechanism

In the technology, the establishment of electronic signature and authentication system is to ensure the authenticity and reliability of the main transaction. Electronic signature is attached to the data in telecommunications or logical connection with the electronic data. Electronic signature can be used to prove the identity of the signed data, and show that the signatories agree that information contained in the data message. The establishment of electronic signature system lies in the effectiveness of legal force to the data message and evidence, so that the judicial organs to correct solving e-commerce disputes.

The electronic signature certification referred to as "certification" or "security", is to verify the legal behavior in a specific organization of the authenticity of the electronic signature. Electronic signature system pays more attention to the data information security, electronic signature authentication emphasizes the relationship between credit transaction securities and to guarantee the true and reliable transaction. 


\section{Electronic commerce attack}

\section{The concept of the attack}

Attack refers to an attacker to inject a user to false recommendation system, in order to make the system of the recommended results. An attack of user data (User Profile, abbreviated as UP) are represented by a $\mathrm{m}$ dimensional vector, i.e.

$$
U P=\left\{r_{1}, r_{2}, r_{3}, \ldots, r_{m}\right\}
$$

I is set in the commodity recommendation system, according to the characteristics of different attack model, by I, and is composed of 4 parts, i.e.

$$
I=i_{t} \cup I_{S} \cup I_{F} \cup I_{\phi}
$$

Among them is the target product, is used to determine the target user increase attack efficiency commodity, is refers to the evaluation value of goods, is not given to evaluate the value of the commodity set. The difference is reflected in the different attack model, and its evaluation value setting. The general form of attack data is described as in figure 1.

\begin{tabular}{|c|c|c|c|c|c|c|c|c|c|}
\hline$i_{1}^{s}$ & $\cdots$ & $i_{k}{ }^{s}$ & $i_{1}^{r}$ & $\cdots$ & $i_{l}^{r}$ & $i_{1}^{\varphi}$ & $\cdots$ & 0 & $i_{t}$ \\
\hline$\delta\left(i_{1}^{s}\right)$ & $\cdots$ & $\delta\left(i_{k}{ }^{s}\right)$ & $\sigma\left(i_{1}^{r}\right)$ & $\cdots$ & $\sigma\left(i_{l}^{r}\right)$ & null & null & null & $r\left(i_{t}\right)$ \\
\hline
\end{tabular}

Figure 1 the general attack model

An attack by a number of attacks on user data, i.e.

Attack $=\left\{U P_{1}, U P_{2}, \ldots, U P_{n-1}, U P_{n}\right\}$

\section{Attack cost}

The attack cost reflects the degree of difficulty and the amount of the attacker attacks, including the cost of knowledge and execution cost. The former refers to the collection of information and user information to pay the system being attacked when the latter refers to the ratio of the number of efforts to attack the need to inject into the system of the attack user data quantity and the system database of existing users of the data - Aggression Scale each user data with I2I attack in the proportion of packing size.

\section{Attack efficiency}

Prediction of incremental changes to describe system is given for the same goods in the attack and the value of the. Average increment is to predict the increment in the user set and the commodity set weighted average. Average increment is bigger, show that the system is vulnerable, or that attack more effective; otherwise, show that the system is stable, the worse the attack effect. But the prediction of incremental high does not indicate that the I will be a commodity recommendation system, but also the other goods forecast the size of the increment. Therefore, foreign scholars have also introduced a new criterion: the hit rate of .

The hit rate of that is the target of goods into the system before the $\mathrm{N}$ recommended probability. Note that the collection system, recommended to the user u $\mathrm{N}$ products, otherwise, for the average user I hit all goods are expressed as

Hit Ratio ${ }_{i}=\sum_{u \in U} H_{u i} /|U|$ 
Similarly, for all the goods hit rate is expressed as

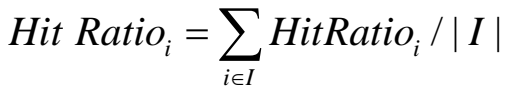

In comparison, the hit rate than the average increment can better reflect the effect of the attack from the intuitive.

\section{Conclusion}

With the arrival of Electronic Commerce, many people have become interested in trust issues. Most people agree that in order for Electronic Commerce to become a success the people have to trust it. In this paper, idea of Electronic Commerce trust is briefly introduced. Concepts, character, attack cost and attack effectiveness of attack are described, and analyzing all kinds of attack model in Electronic Commerce systems.

\section{Acknowledgement}

Supported by University Students' Innovative Undertaking Project of Zhejiang Business Technology Institute.

A Project Supported by Scientific Research Fund of Zhejiang Business Technology Institute (Grant No. 2014Y05).

\section{References}

[1] Songjie Gong, A Collaborative Filtering Recommendation Algorithm Based on Trust Network and Trust Factor, Journal of Convergence Information Technology, Vol. 8, No. 5, pp. $1111 \sim 1118$, 2013.03.

[2] Songjie Gong, Research on Attack on Collaborative Filtering Recommendation Systems, AISS: Advances in Information Sciences and Service Sciences, Vol. 5, No. 10, pp. 938 946, 2013.05

[3] Xue, G., Lin, C., \& Yang, Q., et al. Scalable collaborative filtering using cluster-based smoothing. In Proceedings of the ACM SIGIR Conference 2005 pp.114-121.

[4] D. Bridge and J. Kelleher, Experiments in sparsity reduction: Using clustering in collaborative recommenders, in Procs. of the Thirteenth Irish Conference on Artificial Intelligence and Cognitive Science, pp. 144-149. Springer, 2002.

[5] B. Sarwar, G. Karypis, J. Konstan and J. Riedl, Recommender systems for large-scale e-commerce: Scalableneighborhood formation using clustering, Proceedings of the Fifth International Conference on Computer andInformation Technology, 2002

[6] Songjie Gong, Liping Zeng, The Solution of Safety of Electronic Cash in E-Commerce under Cloud Computing Environment, Advanced Materials Research, Vol. 989, pp: 4314-4317, 2014.

[7] Songjie Gong, Research on the Growth Mechanism of High-Skilled System in Computer Science and Technology, Applied Mechanics and Materials, Vol. 513, pp: 2748-2751, 2014. 